\title{
Gas Semiconducting Sensors Based on Metal Oxide Nanocomposites
}

\author{
L. I. Trakhtenberg \\ Semenov Institute of Chemical Physics, Russian Academia of Sciences \\ Kosygina str., 4. Moscow 119991, Russia \\ G. N. Gerasimov, V. F. Gromov \& T. V. Belysheva \\ Karpov Institute of Physical Chemistry, 10, Vorontsovo Pole Str. \\ Moscow 105064, Russia \\ O. J. Ilegbusi \\ University of Central Florida, 4000 Central Florida Blvd \\ Orlando, FL 32816-2450, USA
}

Received: December 5, 2011 Accepted: December 26, $2011 \quad$ Published: Apri1 1, 2012

doi:10.5539/jmsr.v1n2p56

URL: http://dx.doi.org/10.5539/jmsr.v1n2p56

\begin{abstract}
This paper reviews the important problems associated with the synthesis of metal-oxide nanocomposites, charge transfer phenomena in these composites, their conductive and sensory properties, modeling of sensory effect and the role on this sensory effect of the electronic structure of the metal oxide. The size of metal particles and temperature significantly influence the efficiency of such systems. However, the electronic interactions between the different components of the nanocomposite films play the dominant role in the exploitation of the properties of such sensory systems. Depending on the chemical nature of the analyzed gas and the electronic structure of the semiconducting metal oxides, such interactions can result in either an increase or a decrease of the sensory effect. Thus, by varying the electronic structure of the metal oxide composite sensors as well as the temperature and size of the metal-oxide nanoparticles, the inherent characteristics of the sensor can be changed and tailored for detection of various gases. Such findings clearly open up new opportunities for development of novel selective sensors.
\end{abstract}

Keywords: Conductivity, Electron affinity, Electron transport, Electronic structure, Gas detection, Indium oxide, Metal-oxide, Nanocomposite, Nanoparticle, Semiconductor, Sensor, Sensory properties, Tin oxide

\section{Introduction}

The rapid growth in industrial production and the attendant environmental impact have made it imperative to develop highly sensitive and selective sensors for the detection of various pollutants in the atmosphere.

Conductometric chemical sensors based on nanocrystalline metal-oxide semiconductors are currently the most promising among solid-state gas detectors due to their reliability, and ease of manufacture and application. Miniaturization and low price also enable their use as personal sensors.

The sensitivity of such systems is manifest by the change in conductivity resulting from chemical interaction of adsorbed analyzed gas with active centers on the surface of the sensor. The sensor characteristics, which include sensitivity, response time and selectivity, are largely determined by two factors: the reactivity of active centers of the sensor and the diffusion of gas to these centers.

Previous studies on conductometric metal oxide sensors have mostly focused on systems consisting of single semiconducting metal oxide, mostly $\mathrm{SnO}_{2}$. The disadvantage of such sensors is the rather low selectivity to gases that have similar chemical characteristics, for example, various reducing gases. A promising approach to improve conductometric sensors is the use of composite materials in which nanoparticles of metal oxide 
semiconductor or metal are embedded in an organic polymer or inorganic (mainly semiconductors) matrix. The following sections describe such sensors and discuss the fundamental mechanism underlying the sensory phenomena.

\section{Sensors Based on Polymer Composite}

Various methods have been reviewed of synthesis and properties of polymer composites for sensor applications (Godovski, 1995; Woehrle, 1996; Pomogailo, et al., 2000; Trakhtenberg \& Gerasimov, 2005; Gerasimov \& Trakhtenberg, 2007). The polymer matrix prevents aggregation of nanoparticles of metal and metal oxide embedded in the matrix to form composites with high particle concentration. Conductometric sensory properties are included in such systems by the change in the tunneling electron transfer between the nanoperticles under the influence of substances being sensed, penetrating into the composite film from the environment and adsorbed onto the nanoperticles (Godovski, 1995; Trakhtenberg \& Gerasimov, 2005).

Vorontsov et al. (1998) observed sensor response to low hydrogen pressures at ambient temperature in poly-p-xylylene film containing Pd nanocrystals. The electrical resistance of the film was found to increase under the influence of hydrogen presumably because of dissociative adsorption of hydrogen molecules on the Pd nanocrystals which increases the electron work function of these nanocrystals and consequently increases the barrier to the tunnel electron transfers between the nanocrystals. After removal of the hydrogen the film resistance returns to its initial value within 30-60 seconds, indicating that such films can be used as reversible sensors for hydrogen detection. It was also found that the polymer matrix properties and the concentration of stabilized metal oxide nanoparticles influence the sensitivity of composite films to strongly polar substances. It was shown that this effect depends on the type and structure of the analyte (Sergeev, et al., 1997; Trakhtenberg, et al., 1999; Du \& Ilegbusi, 2004). Thus, the use of polymer composites with semiconductor metal oxide nanoparticles embedded in polymer matrix provides some opportunities to improve the selectivity of metal oxide sensors.

\section{Sensors Based on Mixed Metal Oxides}

Mixed metal oxide systems containing metal oxides of different electronic structure which interact with each other offer much more promise than single oxides for sensitive and selective detection of various gases in the environment (de Lacy Costello, et al., 2002; Tang, et al., 2006; Shouli, et al., 2010; Ivanovskaya, et al., 2003). Interaction between the component of metal oxide systems can lead to a change in the electronic structure of the nanocrystals and, hence, affect their reactivity. It is remarkable that the selectivity of the sensor response can be significantly improved by varying the composition, structure and work functions of such nanocomposite sensors (Yu \& Choi, 2001; Kima, et al., 2007; Shouli, et.al, 2008). In particular, the effect of temperature on the sensitivity of metal oxide nanocomposite sensor to gases in the air varies with sensor composition and type of gas.

A typical example is the data of Yu \& Choi (2001), in which a small amount of $\mathrm{ZnO}$, when added to $1 \mathrm{~mol} \%$ $\mathrm{CuO}$ doped $\mathrm{SnO}_{2}$, shifted the $\mathrm{H}_{2}$ gas-sensing curve in the presence of $\mathrm{CO}$ to a higher temperature. This trend resulted in selective $\mathrm{CO}$ detection in a mixture with $\mathrm{H}_{2}$ at relatively low temperature $\left(\mathrm{SCO} / \mathrm{SH}_{2} \sim 5\right.$ at $\left.160^{\circ} \mathrm{C}\right)$, and selective $\mathrm{H}_{2}$ detection at high temperature $\left(\mathrm{SH}_{2} / \mathrm{SCO} \sim 2\right.$ at $\left.310^{\circ} \mathrm{C}\right)$.

\section{Synthesis of Metal Oxide Nanocomposites}

Mixed metal oxide systems can be classified into three groups. The first category includes chemical compounds resulting from the chemical interaction between various oxides. Examples include $\mathrm{ZnSnO}_{3}$ and $\mathrm{Zn}_{2} \mathrm{SnO}_{4}$ compounds formed in the $\mathrm{ZnO}-\mathrm{SnO}_{2}$ system (Shen \& Zhang, 1993), and the crystal $\mathrm{CdIn}_{2} \mathrm{O}_{4}$ which is an effective sensor for $\mathrm{CO}$, produced by the interaction of $\mathrm{CdO}$ with $\mathrm{In}_{2} \mathrm{O}_{3}$ (Szklarski, et al., 1989). The phase $\alpha$-SnWO ${ }_{4}$, sensitive to small amounts of $\mathrm{CO}$ and $\mathrm{NO}$, was observed in the system $\mathrm{SnO}_{2}-\mathrm{WO}_{3}$ (Solis \& Lantto, 1995). The second category includes mixed oxides, which form solid solutions. An example of such a system is the mixture of $\mathrm{TiO}_{2}$ and $\mathrm{SnO}_{2}$, which form solid solutions over the entire range of compositions but only above a certain critical temperature (Edelman, et al., 2000; Arakawa, et al., 1997). The third group consists of systems that give neither individual compounds nor solid solutions. These systems contain mixtures of metal oxide nanocrystals interacting with each other such as, $\mathrm{In}_{2} \mathrm{O}_{3}-\mathrm{SnO}_{2}, \mathrm{TiO}_{2}-\mathrm{WO}_{3}$ and many others (Chowdhuri, et al., 2002; Neri, et al., 2008; Xu, et al., 2010). In fact, only mixed metal oxides of the third group can be regarded as composite materials. It is such systems that will be discussed in this chapter.

A variety of methods are used for producing mixed metal oxide nanocomposites. These methods include sol-gel technique using codeposition of mixed oxides from corresponding salt solution (Arbiol, et al., 2006), aerosol spraying of salt solutions with subsequent heat treatment (Thangaraju, 2002), the deposition by reactive metal 
sputtering from composite targets in the presence of oxygen (Comini, et al., 2002; Nanto, et al., 1996), and the blending of individual metaloxide nanopowders (Yu \& Choi, 1998). It should be noted that the structure of the nanocrystalline components in the composite may differ significantly from that of individual substances which form the base of the composite. The formation of mixed metal oxide nanocomposites may probably produce nanoparticles with high volume defects resulting mainly from the incorporation of ions of one component in the lattice of another.

Such crystalline particles are produced, for example, in the synthesis of nanocomposite $\mathrm{TiO}_{2}-\mathrm{SnO}_{2}$ by RF-sputtering and by molecular beam. In this case, initially formed amorphous system containing a mixture of titanium and tin ions (Edelman, et al., 2000) transforms into a nanocrystalline composite upon further annealing. When spraying a mixture of $\mathrm{Sn}$ and In salt solutions on the surface of the heated substrate by aerosol method, the synchronous joint growth of crystals of $\mathrm{SnO}_{2}$ and $\mathrm{In}_{2} \mathrm{O}_{3}$ with different crystal lattices produces the composite film, in which the size and state, and in particular, crystal defects strongly depend on the composition of the film and the spraying conditions. Aerosol synthesis has been used to produce composite films in which the conductivity sharply decreases compared to that of pure nanocrystalline $\mathrm{SnO}_{2}$ even at low concentrations of $\mathrm{In}_{2} \mathrm{O}_{3}$ in the composite (Manoj, et al., 2007). This result indicates the introduction of $\mathrm{In}^{+3}$ ions in the crystal lattice of $\mathrm{SnO}_{2}$ with ions $\mathrm{Sn}^{+4}$, accompanied by the formation of electron accepting centers (see, eg, (Yu \& Choi, 2001) ). The formation of formation of sensor films by mixing individual nanocrystalline oxides also precludes the introduction of ions from one oxide into the volume of the other. This method of synthesizing composite films can only change the surface layers of contacting particles. Such a structure of mixed metal oxide films allows us to distinguish among other factors, the effect of contacts between individual crystallites on the conductivity of the composite film and its sensory properties and thus to gain a new insight into the mechanism of sensory mechanism in these systems.

Mixtures consisting of nanocrystalline semiconducting metal oxides with different work function and electron affinity are of special interest among the composites of this type. In such systems contacts between the nanocrystals of different electronic properties lead to the mutual charging of these contacting particles as a result of electron transfer between them. A typical example of such effect is the charge transfer in sensors consisting of semiconductor particles of p- and n-type (Gleiter, et al., 2001). Charge transfer processes, as will be shown below, have a strong influence on the sensory effect.

\section{Charge Transfer Processes}

Many p-type oxides form p-n junctions with $\mathrm{SnO}_{2}$ (n-type). It has been shown that the work function of $\mathrm{SnO}_{2}$ is increased significantly by loading with p-type metal oxides, for example, $\mathrm{PdO}$ (about $0.1 \mathrm{eV}), \mathrm{Ag}_{2} \mathrm{O}(0.3 \mathrm{eV})$ and $\mathrm{CuO}(0.5 \mathrm{eV})$. The data in parentheses show how much the $\mathrm{SnO}_{2}$ work function increases due to electron transfer from $\mathrm{SnO}_{2}$ to the p-type metal oxides cited (Matsushima, et al., 1988), which is accompanied by lowering of the Fermi level of $\mathrm{SnO}_{2}$ (Klein, et al., 2010)

The X-Ray Photoelectron Spectroscopy (XPS) method allows the interaction between the components of nanocomposite systems and charge transfer between them to be readily established. XPS analysis was used to determine the surface electronic states of $\mathrm{Sn}$ and $\mathrm{In}$ ions in $\mathrm{In}_{2} \mathrm{O}_{3}+\mathrm{SnO}_{2}$ composite (Aifan, et al., 2006). The composite was obtained by co-deposition mixture of chlorides of tin and indium, followed by annealing in air at $600^{\circ} \mathrm{C}$

It should be noted that the two components in this composite are both n-type semiconductors, but they differ significantly in the work function and electron affinity. In such a system containing $40 \% \mathrm{In}_{2} \mathrm{O}_{3}$, significant positive chemical shifts have been observed, of $0.6 \mathrm{eV}$ and $0.5 \mathrm{eV}$ in the $\mathrm{Sn} 3 \mathrm{~d} 5 / 2$ and $\mathrm{O}$ 1s peaks, respectively, relative to pure $\mathrm{SnO}_{2}$. Such shifts are caused by the transition of electrons from $\mathrm{In}_{2} \mathrm{O}_{3}$ particles to $\mathrm{SnO}_{2}$ particles, accompanied by the formation of charged $\mathrm{In}_{2} \mathrm{O}_{3}{ }^{+}$and $\mathrm{SnO}_{2}{ }^{-}$nanocrystals contacting each other. The increasing concentrations of electrons and the existence of negative charge on the $\mathrm{SnO}_{2}$ particles lead to downward bending of the conduction and valence bands. This result is accompanied by an increase in bonding energy of Sn and O ions in the lattice of $\mathrm{SnO}_{2}$ with a corresponding shift of the bands in the XPS spectra (see, e.g., (Yang, et al., 2006, Aifan, et al., 2008)). Correspondingly, a decrease in the binding energy of the In and O ions should be observed in the $\mathrm{In}_{2} \mathrm{O}_{3}{ }^{+}$lattice due to lowering of the electron density in the $\mathrm{In}_{2} \mathrm{O}_{3}{ }^{+}$crystals.

\section{Sensory Phenomena in Composites}

The interaction between the composite components produces significant sensory effect. Klein, et al., (2010) shows that the $\mathrm{In}_{2} \mathrm{O}_{3}+\mathrm{SnO}_{2}$ composite containing $20 \%$ to $40 \% \mathrm{In}_{2} \mathrm{O}_{3}$ has a much higher sensitivity to CO compared with sensors based on pure nanocrystalline $\mathrm{In}_{2} \mathrm{O}_{3}$ and $\mathrm{SnO}_{2}$. Mutual charging of the components of the metal oxide $\mathrm{In}_{2} \mathrm{O}_{3}+\mathrm{Ag}_{2} \mathrm{O}$ nanocomposite has been found (Mehta \& Singh, 2005). The $\mathrm{Ag}_{2} \mathrm{O}$ oxide is a 
p-semiconductor and forms pn junction with $\operatorname{In}_{2} \mathrm{O}_{3}$. The conduction electrons of $\operatorname{In}_{2} \mathrm{O}_{3}$ are drawn toward $\mathrm{Ag}_{2} \mathrm{O}$, producing an electron-depleted layer in the $\mathrm{In}_{2} \mathrm{O}_{3}$ nanoparticle resulting in an increased electrical resistance. It is important to note that $\mathrm{In}_{2} \mathrm{O}_{3}-\mathrm{Ag}_{2} \mathrm{O}$ composite containing $15 \% \mathrm{Ag}_{2} \mathrm{O}$ is significantly more effective in detecting ethanol than pure $\mathrm{In}_{2} \mathrm{O}_{3}$.

The modification of nanocrystalline $\operatorname{In}_{2} \mathrm{O}_{3}$ with rubidium carbonate $\left(\mathrm{Rb}_{2} \mathrm{CO}_{3}\right)$ has been observed to increase the sensitivity in the detection of $\mathrm{CO}$ and $\mathrm{H}_{2}$. This finding is associated with the change in the electronic structure of the nanocomposite. Semiconducting crystals of $\mathrm{Rb}_{2} \mathrm{CO}_{3}$ relate to p-type semiconductor. The p-n-contacts between the $\mathrm{Rb}_{2} \mathrm{CO}_{3}$ and $\mathrm{In}_{2} \mathrm{O}_{3}$ in this system result in the transfer of electrons from $\operatorname{In}_{2} \mathrm{O}_{3}$ to $\mathrm{Rb}_{2} \mathrm{CO}_{3}$. As a result, XPS spectroscopy indicates that the binding energies of indium and oxygen ions in the lattice of $\operatorname{In}_{2} \mathrm{O}_{3}$ decrease, while the binding energy of the $\mathrm{Rb}$ ions in the $\mathrm{Rb}_{2} \mathrm{CO}_{3}$ lattice increases (Yamaura, et al., 1996).

Lee et al., (2001) investigated nanocomposite sensor in which the $\operatorname{In}_{2} \mathrm{O}_{3}$ particles were covered by layers of cobalt oxide. XPS was used to establish charge transfer between contacting nanocrystals of $\mathrm{CoO}$ (p-semiconductor) and $\mathrm{In}_{2} \mathrm{O}_{3}$ (n-semiconductor), which leads to a significant increase in sensitivity of the composite sensor for detection of $\mathrm{CO}$ in comparison with the sensitivity of pure $\operatorname{In}_{2} \mathrm{O}_{3}$. The interaction between the nanocrystalline components of a mixed metal oxide system, accompanied by electron transfer, was also observed in a composite, consisting of electron donor $\mathrm{In}_{2} \mathrm{O}_{3}$ particles and electron accepting $\mathrm{CeO}_{2}$ particles $(\mathrm{Xu}$, et al., 2010). Nanocomposite containing $25 \% \mathrm{CeO}_{2}$, produced a three-fold greater sensitivity to $\mathrm{H}_{2} \mathrm{~S}$ and ethanol than pure $\operatorname{In}_{2} \mathrm{O}_{3}$.

A detailed study has been done of sensory properties of semiconducting $\mathrm{SnO}_{2}+\mathrm{In}_{2} \mathrm{O}_{3}$ metal oxide systems for detection of $\mathrm{H}_{2}$ and $\mathrm{CO}$ (Belysheva, et al., 2010b, 2011). In these studies, the composite films were obtained by mixing nanocrystalline powders of individual oxides in aqueous media in a ball mill and subsequently annealing at $550-600^{\circ} \mathrm{C}$. X-ray data indicate that the average size of $\mathrm{SnO}_{2}$ crystals in the film was $50-70 \mathrm{~nm}$, and the size of the $\mathrm{In}_{2} \mathrm{O}_{3}$ crystals was $30-40 \mathrm{~nm}$.

There may be a variety of paths leading to conductivity with the participation of nanocrystals in mixed metal oxide semiconductor nanocomposite systems. Sensory effect depends on which path the current flows in the mixture. Therefore, the conductivity was investigated in nanocrystalline $\mathrm{SnO}_{2}+\mathrm{In}_{2} \mathrm{O}_{3}$ system with varying concentration of the components over a wide temperature range (Belysheva, et al., 2010a). The following section describes the modeling of sensory phenomena based on such data.

\section{Modeling Sensory Phenomena}

In reviewing the data on the conductivity and sensory effects in Belysheva et al., (2010a, b, 2011), a common model of nanocrystalline sensor (Yamazoe \&. Shimanoe, 2008) has been used whereby the conductivity of a film consisting of metal oxide particles is due to the transfer of electrons between the particles and determined by the conduction electrons concentration (ns) on the surface of the particles. Chemisorption of molecular oxygen from the air at the particle surface is accompanied by the capture of semiconductor conduction electrons and the formation of negatively charged surface oxygen centers $\left(\mathrm{O}_{2}^{-}, \mathrm{O}^{-}\right)$. It is assumed that these centers form the averaged uniform electric field, which creates a barrier to exit conduction electrons on the surface, resulting in sharp reduction of ns, and respectively, decreased sensor conductivity. Sensor effect for reducing gases is attributed to the reaction of such gases with surface oxygen centers, leading to the consumption of the oxygen adsorbate, accompanied by a corresponding mitigation in barrier and an increase in conductivity. This model allows ready description of many of the sensory phenomena. Unfortunately, it remains unclear whether enough electrons are trapped by oxygen atoms to form a barrier for the transfer of conduction electrons between the nanoparticles.

\section{Conductivity of Composite Films}

The conductivity of $\mathrm{SnO}_{2}$ films increases with temperature in the temperature range $200-550^{\circ} \mathrm{C}$ according to the Arrhenius law, with the conductivity activation energy being $10.8 \mathrm{kcal} / \mathrm{mol}$. The conductivity of $\operatorname{In}_{2} \mathrm{O}_{3}$ films increases slightly with temperature in the range $150-250^{\circ} \mathrm{C}$, drops sharply in the range $250-400{ }^{\circ} \mathrm{C}$, and subsequently increases at temperatures above $400{ }^{\circ} \mathrm{C}$. A similar trend was also observed in a previous study of $\mathrm{In}_{2} \mathrm{O}_{3}$ film synthesized by the spray method (Korotcenkov, et al., 2001, 2004). The decrease in the conductivity of $\mathrm{In}_{2} \mathrm{O}_{3}$ films with increasing temperature can be explained within the framework of the model described above. Specifically, it is associated with the change in the nature of the oxygen centers, chemisorbed on the surface of metal oxide nanoparticles and creating a barrier to electron transfer between the particles of the film.

The dependence of conductivity on temperature for nanocrystalline composite films with low concentration (up to $20 \%$ ) of $\mathrm{In}_{2} \mathrm{O}_{3}$ crystals in crystalline $\mathrm{SnO}_{2}$ medium (Figure 1a) is similar to the smooth curve observed for 
films of pure $\mathrm{SnO}_{2}$. The data obtained lead to the conclusion that the electrical current induced in these films flows through the $\mathrm{SnO}_{2}$ nanocrystals, however, additives of $\mathrm{In}_{2} \mathrm{O}_{3}$ nanocrystals produce an increase in film conductivity. A similar effect was also observed for the $\mathrm{SnO}_{2}+\mathrm{In}_{2} \mathrm{O}_{3}$ system in the $\mathrm{In}_{2} \mathrm{O}_{3}$ concentration range 0 $20 \%$ (Neri, et al., 2008).

The observed effect of composition of the mixed metal oxide $\mathrm{SnO}_{2}+\mathrm{In}_{2} \mathrm{O}_{3}$ film on conductivity is due to mutual charging of the $\mathrm{SnO}_{2}$ and $\mathrm{In}_{2} \mathrm{O}_{3}$ particles, similar to the hole and electron conductivity in a mixture of semiconductor particles (Gleiter, et al., 2001): $\mathrm{SnO}_{2}$ particles are negatively charged, and $\mathrm{In}_{2} \mathrm{O}_{3}$ particles acquire a positive charge. A schematic representation of electron movement in $\mathrm{SnO}_{2}+\mathrm{In}_{2} \mathrm{O}_{3}$ nanocomposite system is shown in Figure 2. It should be noted however, that the charges in contacting particles are not distributed uniformly over the volume of particles, but are concentrated near the contact zone. Belysheva et al. (2010a) have shown that as a first approximation, the conductivity through the $\mathrm{SnO}_{2}$ particles in films containing low concentrations of $\operatorname{In}_{2} \mathrm{O}_{3}$ particles can be represented as the sum of the conductivities along two parallel tracks: (BI) through the neutral particles of the nanocrystalline $\mathrm{SnO}_{2}$ matrix (away from contact with $\mathrm{In}_{2} \mathrm{O}_{3}$ ) and (BII) through the negatively charged $\mathrm{SnO}_{2}$ particles contacting with positively charged $\mathrm{In}_{2} \mathrm{O}_{3}$ particles.

Conductivity (BII) occurs when the percolation threshold of the charged $\mathrm{SnO}_{2}$ clusters has been overcome. Estimates made in Belysheva et al. (2010b) suggest that this threshold must be overcome even when the concentration of $\mathrm{In}_{2} \mathrm{O}_{3}$ particles is about 3\%. However, judging from the data (Belysheva, et al., 2010a), the contribution of the second conduction path to the total conductivity at low concentrations ${ }^{2} \operatorname{In}_{2} \mathrm{O}_{3}$ particles in the composite is not readily visible and indeed becomes significant only at $\operatorname{In}_{2} \mathrm{O}_{3}$ concentrations about $10 \%$. Following the explanation provided in Belysheva et al., (2010a), the activation energy of conduction through a negatively charged $\mathrm{SnO}_{2}$ in the nanocomposite is probably lower than that through usual neutral matrix. This is due to downward bending of the $\mathrm{SnO}_{2}$ conduction band as a result of enrichment with electrons of the $\mathrm{SnO}_{2}$ particles contacting with $\mathrm{In}_{2} \mathrm{O}_{3}$ particles. The existence of two paths of conductivity through the $\mathrm{SnO}_{2}$ particles with different activation energies leads to the deviation of the temperature dependence of the conductivity from Arrhenius law (Figure 1a).

There is a remarkable change in the temperature dependence of composite film conductivity at $\operatorname{In}_{2} \mathrm{O}_{3}$ concentration of about $20 \%$. Specifically, the conductivity decreases with temperature in the range $250-400{ }^{\circ} \mathrm{C}$, which is characteristic of a nanocrystalline film of pure $\operatorname{In}_{2} \mathrm{O}_{3}$ (Figure 1b). This result indicates there is a new path for current flow through the conducting cluster of $\operatorname{In}_{2} \mathrm{O}_{3}$ nanocrystals, pervading the entire space between the electrodes within the film. Considering that the conductivity of $\operatorname{In}_{2} \mathrm{O}_{3}$ is three orders of magnitude higher than that of $\mathrm{SnO}_{2}$, the $\mathrm{In}_{2} \mathrm{O}_{3}$ particles can be regarded as quasimetallic inclusions in the $\mathrm{SnO}_{2}$ matrix. According to the theory of percolation in a random close-packed mixture of metallic and dielectric spheres, metallic conductivity occurs when the metal concentration is approximately $25 \mathrm{vol} \%$ (Efros, 1982). Thus the data of Belysheva et al. (2010a) as a first approximation is consistent with the theory. The reduction in resistance with further increase in $\operatorname{In}_{2} \mathrm{O}_{3}$ concentration in the composite is due to the branching of the conducting cluster and increase in the number of paths for current flow (Efros, 1982).

\section{Sensory Mechanism}

Conductivity largely determines the sensory phenomena observed in nanocrystaline $\mathrm{SnO}_{2}+\operatorname{In}_{2} \mathrm{O}_{3}$ films. The effect of composition on sensory characteristics of such films had been investigated for the detection of hydrogen and carbon monoxide (Belysheva, et al., 2010b, 2011). The temperature dependence of the sensitivity $\mathrm{S}(\mathrm{S}=\mathrm{Ro} / \mathrm{R}$, where Ro and $\mathrm{R}$ are the sensor resistance in pure air and in air containing analyzed gas, respectively) has been shown to be typical for such sensors, and characterized by a maximum $\left(\mathrm{S}_{\max }\right)$ at a certain temperature $\left(\mathrm{T}_{\text {max }}\right)$. It is remarkable that the sensitivity of $\operatorname{In}_{2} \mathrm{O}_{3}$ nanocrystalline films reaches a maximum value at a much lower temperature than that of $\mathrm{SnO}_{2}$ film for the detection of the hydrogen and carbon monoxide gases.

The sensitivity of $\mathrm{SnO}_{2}$ films for the detection of $\mathrm{CO}$ in air is considerably lower than the sensitivity of $\mathrm{In}_{2} \mathrm{O}_{3}$ film (Belysheva, et al., 2011). The temperature dependence of Smax on the $\operatorname{In}_{2} \mathrm{O}_{3}$ concentration for detection of $\mathrm{CO}$ with the $\mathrm{SnO}_{2}+\mathrm{In}_{2} \mathrm{O}_{3}$ nanocomposite films investigated is shown in curve 1 of Figure 3. Introduction of a small quantity (up to 20\%) of $\mathrm{In}_{2} \mathrm{O}_{3}$ nanocrystals to nanocrystalline $\mathrm{SnO}_{2}$ film leads to an increase in $\mathrm{S}_{\max }$. Considering that in these composite films, as noted above, the current flows through the $\mathrm{SnO}_{2}$ nanocrystals, this phenomenon is due to increase in film sensitivity to $\mathrm{CO}$ of the conducting cluster of negatively charged $\mathrm{SnO}_{2}$ particles in contact with positively charged $\mathrm{In}_{2} \mathrm{O}_{3}$ particles (Figure 2a). Based on the data of Haouas et al. (1993), one of the reasons for this increase in sensitivity can be the increase in CO adsorption capacity of the contact zone between the charged particles of $\mathrm{SnO}_{2}$ and $\mathrm{In}_{2} \mathrm{O}_{3}$. 
The above conductivity data on mixed oxide films indicate that for $\mathrm{In}_{2} \mathrm{O}_{3}$ concentration greater than $20 \%$, the $\mathrm{In}_{2} \mathrm{O}_{3}$ particles connecting to one another form a conducting path spanning the entire sample and in so doing, the percolation threshold for these particles is overcome. Since the conductivity and sensitivity to $\mathrm{CO}$ of $\operatorname{In}_{2} \mathrm{O}_{3}$ clusters are significantly higher than the corresponding properties for the surrounding $\mathrm{SnO}_{2}$ matrix, the sensory properties of the $\mathrm{In}_{2} \mathrm{O}_{3}$ clusters largely govern those of the $\mathrm{SnO}_{2}+\mathrm{In}_{2} \mathrm{O}_{3}$ composite. Figure 3 shows that, with increasing concentration of $\mathrm{In}_{2} \mathrm{O}_{3}$ in the film from 20 to $50 \%$ the value of $\mathrm{S}_{\max }$ of the composites investigated remains mostly constant, and differs very little from the Smax for a film of pure $\operatorname{In}_{2} \mathrm{O}_{3}$.

It should be noted that $\mathrm{S}_{\max }$ depends on the cluster surface on which oxygen and the analyzed gas are adsorbed. Probably, with increasing $\operatorname{In}_{2} \mathrm{O}_{3}$ concentration in the film, the total surface of $\operatorname{In}_{2} \mathrm{O}_{3}$ clusters grows to a certain limit beyond which any increase of the surface area due to formation of new clusters is balanced by the surface diminution resulting from their aggregation. Similar effects were observed during the formation of a new phase (see, e.g., (Zaporojtchenko, et al., 1999; Blackman, 1995)). This finding explains why $\mathrm{S}_{\max }$ of the mixed oxide composite film remains unchanged over the range of indium concentration from 20 to $50 \%$.

The value of temperature Tmax corresponding to Smax for the $\mathrm{SnO}_{2}+\mathrm{In}_{2} \mathrm{O}_{3}$ sensors applied for detection of CO does not depend on the $\mathrm{In}_{2} \mathrm{O}_{3}$ concentration in the range $20 \%$ to $37 \%$ and it is significantly higher than the Tmax $\left(\mathrm{In}_{2} \mathrm{O}_{3}\right)$ for pure $\operatorname{In}_{2} \mathrm{O}_{3}$. Calculations based on the established model of metal oxide sensor conductivity (Yamazoe \& Shimanoe, 2008) considering the influence of Langmuir adsorption on sensory effect, discussed in (Ahler, et al., 2005), shows that the $\mathrm{T}_{\max }$ value increases with increase in the heat of gas adsorption on the surface of the sensor (Belysheva et al., 2011). As noted above the contacts between $\mathrm{SnO}_{2}$ and $\operatorname{In}_{2} \mathrm{O}_{3}$ particles in the composite film lead to their mutual charging: $\mathrm{SnO}_{2}$ particles become negatively charged, and $\operatorname{In}_{2} \mathrm{O}_{3}$ particles acquire a positive charge. It is reasonable to assume that the heat of adsorption of polar $\mathrm{CO}$ molecules on charged particles of $\operatorname{In}_{2} \mathrm{O}_{3}$ and $\mathrm{SnO}_{2}$ is higher than that on neutral particles. Therefore, until $\mathrm{In}_{2} \mathrm{O}_{3}$ clusters which determine the conductivity and sensitivity of the $\mathrm{SnO}_{2}+\mathrm{In}_{2} \mathrm{O}_{3}$ composite sensor to gas, are surrounded by a matrix of $\mathrm{SnO}_{2}$, the Tmax value for such sensors would be higher than $\mathrm{T}_{\max }\left(\operatorname{In}_{2} \mathrm{O}_{3}\right)$. When the concentration of $\mathrm{In}_{2} \mathrm{O}_{3}$ in the composite reaches $50 \%$, there is, apparently, a reorganization of the composite, and clusters of $\operatorname{In}_{2} \mathrm{O}_{3}$ form a separate phase. Consequently, the influence becomes negligible of $\mathrm{SnO}_{2}$ on the sensory phenomena in these clusters. In addition, the $\mathrm{T}_{\max }$ of the composite sensor becomes equal to $\operatorname{Tmax}\left(\operatorname{In}_{2} \mathrm{O}_{3}\right)$ as depicted in Figure 4.

The sensitivity of $\mathrm{In}_{2} \mathrm{O}_{3}$-sensor applied for $\mathrm{H}_{2}$ detection is significantly lower than the sensitivity of $\mathrm{SnO}_{2}$. The introduction to the $\mathrm{SnO}_{2}$ film of up to $20 \%$ of $\mathrm{In}_{2} \mathrm{O}_{3}$-nanocrystals results in a significant increase in sensitivity of the composite sensor. A further increase $\operatorname{In}_{2} \mathrm{O}_{3}$ concentration in the composite up to $50 \%$ is initially accompanied by a decrease in sensitivity, and subsequently remains constant at a value equal to the sensitivity of pure $\operatorname{In}_{2} \mathrm{O}_{3}$ (Figure 3, curve 2).

Sensor response to hydrogen, as indicated in the study (Kohl, 1989) is due to the dissociative chemisorption of hydrogen on the surface of the nanocrystalline sensor films with subsequent migration of hydrogen atoms formed along the sensor surface and their reaction with oxygen centers. This reaction lowers the barrier to electron transfer between the particles in the film. Published data (Chowdhuri, et al., 2004) suggest that the dissociation of hydrogen proceeds more efficiently when its chemisorption occurs in the charged boundary regions formed as a result of contact between the $\mathrm{SnO}_{2}$ and $\mathrm{In}_{2} \mathrm{O}_{3}$ particles. This explains the increase in sensitivity to $\mathrm{H}_{2}$ with $\mathrm{In}_{2} \mathrm{O}_{3}$ concentration in the composite sensor containing up to $20 \% \mathrm{In}_{2} \mathrm{O}_{3}$. Specifically, the increase in conductivity is due to increase in charged regions involved in the conduction process.

As indicated earlier, at higher concentration of $\operatorname{In}_{2} \mathrm{O}_{3}$ particles (above the percolation threshold) the current flow path in the composite film is through the conductive clusters of $\operatorname{In}_{2} \mathrm{O}_{3}$ nanocrystals. It should be noted that these clusters (threads) have a small diameter, roughly equal to the diameter of the particles $(50 \mathrm{~nm})$, and at low concentrations of $\operatorname{In}_{2} \mathrm{O}_{3}$ in the composite film the number of threads is quite small. Therefore, the transition from conduction through $\mathrm{SnO}_{2}$ particles to conduction through $\mathrm{In}_{2} \mathrm{O}_{3}$ particles with increasing concentration of $\operatorname{In}_{2} \mathrm{O}_{3}$ in the film, occurs gradually in the region from 20 to $50 \%$, where there are parallel paths of conduction through threads of $\mathrm{In}_{2} \mathrm{O}_{3}$ particles and through surrounding $\mathrm{SnO}_{2}$ matrix, as shown in the a previous study (Manoj, 2007).

Since the sensitivity of $\mathrm{SnO}_{2}$ to $\mathrm{CO}$ is much lower than that of $\mathrm{In}_{2} \mathrm{O}_{3}$ in the range of $\operatorname{In}_{2} \mathrm{O}_{3}$ concentrations above the percolation threshold for $\operatorname{In}_{2} \mathrm{O}_{3}$ particles, the sensitivity of the mixed metal oxide system to $\mathrm{CO}$ is completely determined by the effect of $\mathrm{CO}$ on conductivity of the $\mathrm{In}_{2} \mathrm{O}_{3}$ clusters and largely independent of the $\mathrm{SnO}_{2}$ matrix.

By the same token, the sensitivity of $\mathrm{SnO}_{2}$ to $\mathrm{H}_{2}$ for is much large than that for $\mathrm{In}_{2} \mathrm{O}_{3}$. Therefore, when $\mathrm{SnO}_{2}+$ $\mathrm{In}_{2} \mathrm{O}_{3}$ composite sensors are used for detection of $\mathrm{H}_{2}$ in air, a significant contribution of sensor phenomena in the $\mathrm{SnO}_{2}$ matrix to overall sensory property is retained even with relatively minor contribution of $\mathrm{SnO}_{2}$ conductivity 
to the overall composite conductivity at $\operatorname{In}_{2} \mathrm{O}_{3}$ concentration above the percolation threshold for $\operatorname{In}_{2} \mathrm{O}_{3}$ particles. With increasing concentration of $\operatorname{In}_{2} \mathrm{O}_{3}$ above $20 \%$, the contribution of sensor phenomena in the $\mathrm{SnO}_{2}$ matrix is reduced and, accordingly, in this composition range the sensitivity of the composite sensor to hydrogen gradually decreases (Figure 3). When the concentration of $\mathrm{In}_{2} \mathrm{O}_{3}$ is equal to or greater than $50 \%$ the conductivity of the composite proceeds completely through the $\operatorname{In}_{2} \mathrm{O}_{3}$ particles (Belysheva, et al., 2010a), and the sensitivity of the composite sensor is the same as in pure $\mathrm{In}_{2} \mathrm{O}_{3}$.

The results obtained in the recent studied (Belysheva, et al., 2010a, 2010b, 2011) therefore lead to the conclusion that the specific effects of the composition of mixed $\mathrm{SnO}_{2}-\mathrm{In}_{2} \mathrm{O}_{3}$ films on sensitivity to $\mathrm{CO}$ and $\mathrm{H}_{2}$ is due to the electron transfer between contacting $\mathrm{In}_{2} \mathrm{O}_{3}$ and $\mathrm{SnO}_{2}$ particles and the resulting mutual charging of these particles. This effect is more pronounced in the detection of $\mathrm{H}_{2}$ than the detection of $\mathrm{CO}$. This trend appears to be associated with the more efficient dissociative chemisorption of hydrogen in the charged surface areas on the border between the particles of $\mathrm{In}_{2} \mathrm{O}_{3}$ and $\mathrm{SnO}_{2}$.

\section{The Role of Electron Affinity}

The results of the study (Belysheva, et al., 2010a, 2010b, 2011) characterize the effect on sensory properties of the resulting composites of nanocrystalline electron donor additives $\left(\operatorname{In}_{2} \mathrm{O}_{3}\right.$ with electron affinity of $3.7 \mathrm{eV}$ (Klein, 2000)) embedded in electron accepting matrix $\left(\mathrm{SnO}_{2}\right.$ with the electron affinity of about $4.8 \mathrm{eV}$ (Hoefer, et al., 2001)). The detection of hydrogen and $\mathrm{CO}$ was also investigated utilizing sensors consisting of electron donor matrix $\left(\mathrm{In}_{2} \mathrm{O}_{3}\right)$ with inclusions of nanocrystals of electron accepting component $(\mathrm{ZnO})$. Published data show that the electron affinity of $\operatorname{In}_{2} \mathrm{O}_{3}$ matrix is much smaller than electron affinity of $\mathrm{ZnO}(4,35 \mathrm{eV}(\mathrm{He}$, et al., 2007)). These systems were synthesized using a technique similar to that used for the $\mathrm{SnO}_{2}-\mathrm{In}_{2} \mathrm{O}_{3}$ nanocomposite sensors.

In contrast to the $\mathrm{SnO}_{2}-\mathrm{In}_{2} \mathrm{O}_{3}$ system, a strong influence was observed of electron accepting additives of $\mathrm{ZnO}$ on sensory properties of $\operatorname{In}_{2} \mathrm{O}_{3}$ nanocrystalline films even at low concentrations of $\mathrm{ZnO}$ in the film. For example, it was found that the addition of $1 \% \mathrm{ZnO}$ in the $\mathrm{In}_{2} \mathrm{O}_{3}$ film produces a sharp increase in sensitivity to $\mathrm{H}_{2}$ and a shift in Tmax to lower temperatures, as well as significant reduction in sensitivity to CO (Figure 5). The additive introduced in this composite system, as indicated in (Yamazoe \& Shimanoe, 2009), is likely in the form of small crystal clusters of $\mathrm{ZnO}$, located at the surface of the $\mathrm{In}_{2} \mathrm{O}_{3}$ crystals. Sensory reactions of hydrogen or carbon monoxide with the active $\mathrm{O}^{-}$centers proceeds both in the zone of contact between $\mathrm{ZnO}$ and $\operatorname{In}_{2} \mathrm{O}_{3}$, and on the surface of $\mathrm{In}_{2} \mathrm{O}_{3}$ crystals free of $\mathrm{ZnO}$. The redistribution of electrons between $\mathrm{ZnO}$ and $\operatorname{In}_{2} \mathrm{O}_{3}$ results in negatively charged $\mathrm{ZnO}$ clusters and positively charged $\mathrm{In}_{2} \mathrm{O}_{3}$ crystal zones, associated with the clusters. This in turn leads to a large potential barrier that prevents the transfer of electrons from the $\operatorname{In}_{2} \mathrm{O}_{3}-\mathrm{ZnO}$ contact zone to the free surface of $\operatorname{In}_{2} \mathrm{O}_{3}$. Therefore, in the contact zones the sensory reaction $\mathrm{A}+\mathrm{O}^{-}=\mathrm{AO}+\mathrm{e}^{-}$, where $\mathrm{A}$ is the analyzed gas, has little effect on the surface concentration of electrons in the $\mathrm{ZnO}$-free areas of the $\operatorname{In}_{2} \mathrm{O}_{3}$ particles. These electrons at low concentrations of additives also determine the conductivity of the composite sensor, and changes in surface electron density in the $\mathrm{ZnO}$-free areas under the influence of the analyzed gas induce the conductometric sensor effect.

As mentioned above, the data from the study (Haouas, et al., 1993) indicate that a significant proportion of polar carbon monoxide molecules adsorbed on the surface of $\operatorname{In}_{2} \mathrm{O}_{3}$ can be assumed to be concentrated in areas of contact between electron donor $\operatorname{In}_{2} \mathrm{O}_{3}$ and electron acceptor crystalline $\mathrm{ZnO}$ clusters. The reaction characteristics of the analyzed gas with the oxygen centers in these areas lead to the conclusion that the essential part of the adsorbed $\mathrm{CO}$ actually counteracts the sensory process. This explains the observed decrease in sensitivity to $\mathrm{CO}$ of $\mathrm{In}_{2} \mathrm{O}_{3}$ nanocrystalline containing small additions of $\mathrm{ZnO}$.

The existence of small clusters of $\mathrm{ZnO}$ on the surface of $\mathrm{In}_{2} \mathrm{O}_{3}$ is not to significantly affect the adsorption capacity of these particles for non-polar $\mathrm{H}_{2}$ molecules. The enhancement of sensitivity to hydrogen in this case, as well as in the $\mathrm{SnO}_{2}-\mathrm{In}_{2} \mathrm{O}_{3}$ system, is probably due to an increase in the rate of dissociation of hydrogen in the charged contact zone between the $\mathrm{ZnO}$ clusters and $\mathrm{In}_{2} \mathrm{O}_{3}$ particles. The hydrogen atoms generated migrate from the contact zone to the surface of the $\operatorname{In}_{2} \mathrm{O}_{3}$ particle. This in turn leads to an increase in both the rate of sensory reaction and conductometric sensor response.

It should be emphasized that the sensor system consisting of $\operatorname{In}_{2} \mathrm{O}_{3}$ nanocrystals with $\mathrm{ZnO}$ inclusions, fundamentally differs from the $\mathrm{SnO}_{2}-\mathrm{In}_{2} \mathrm{O}_{3}$ composite sensor described above. In the latter sensor with the relatively small (up to 20\%) concentration of electron donor $\mathrm{In}_{2} \mathrm{O}_{3}$ nanocrystals in $\mathrm{SnO}_{2}$ matrix, current flows through the set of electron accepting $\mathrm{SnO}_{2}$ crystals Electron transfer from $\mathrm{In}_{2} \mathrm{O}_{3}$ to $\mathrm{SnO}_{2}$ crystals does not diminish, but, on the contrary, increases the conductivity of the composite film. Correspondingly, the sensory 
reaction occurring in the contact zone between the $\mathrm{SnO}_{2}$ and $\mathrm{In}_{2} \mathrm{O}_{3}$ crystals and liberating electrons in this zone, as indicated above, leads to increased sensitivity of the sensor.

\section{Conclusion}

The data presented in this chapter indicate that the electronic interactions between the components of metal oxide semiconductor composite sensors play important role in the conductivity and sensory properties of these systems. Such interactions can result in both an increase and a decrease in the sensory effect, depending on the chemical structure of the analyzed gas and the electronic structure of the semiconducting metal oxides utilized in the composite. Thus, by varying the electronic structure of the metal oxide composite sensors their inherent characteristics can be changed and tailored for detection of various gases. Such findings clearly open up new opportunities for development of novel selective sensors.

\section{Acknowledgements}

This study was partially supported by the US National Science Foundation under grant CMMI-1030689, Russian Fund of Basic Research (grants 10-03-00274 and 11-07-00191) and contract 16.513.11.3065 with Federal Agency of Science and Innovations of the Russian Federation.

\section{References}

Ahlers, S., Muller, G., \& Doll, T. (2005). A rate equation approach to the gas sensitivity of thin film metal oxide materials. Sensors and Actuators, B107, 587-599. http://dx.doi.org/10.1016/j.snb.2004.11.020

Aifan, C., Xiaodong, H., Zhangfa, T., Shouli, B., Ruixian, L., \& Chium, L. (2006). Preparation, characterization and gas-sensing properties of $\mathrm{SnO}_{2}-\mathrm{In}_{2} \mathrm{O}_{3}$ nanocomposite oxides. Sensors and Actuators, B115, 316-321. http://dx.doi.org/10.1016/j.snb.2005.09.015

Aifan, C., Shouli, B., Bingjie, S., Zhiyong, L., Dianqing, L., Chung, \& Chiun, L. (2008). Methane gas-sensing and catalytic oxidation activity of $\mathrm{SnO}_{2}-\mathrm{In}_{2} \mathrm{O}_{3}$ nanocomposites incorporating $\mathrm{TiO}_{2}$. Sensors and Actuators, B135, 7-12. http://dx.doi.org/10.1016/j.snb.2008.06.050

Arakawa, S., Mogi, K., Kikuta, K., Yogo, T., Hirano, S., Seki, Y., \& Kawamoto, M. (1997). Phase Separation of Alkoxy-derived (Ti,Sn) $\mathrm{O}_{2}$ Oriented Thin Films. J. Am. Ceram. Soc., 80, $2864-2668$. http://dx.doi.org/10.1111/j.1151-2916.1997.tb03204.x

Arbiol, J., Morante, J., Bouvier, P., Pagnier, T., Makeeva E. A., Rumyantseva, M. N., \& Gaskov, A. M. (2006). $\mathrm{SnO}_{2} / \mathrm{MoO}_{3}$-nanostructure and alcohol detection. Sensors and Actuators, B118, $156-162$. http://dx.doi.org/10.1016/j.snb.2006.04.021

Belysheva, T., Gerasimov, G., Gromov, V., Spiridonova, E., \& Trakhtenberg. L. (2010a). Resistivity of nanocomposite crystalline $\mathrm{SnO}_{2}-\mathrm{In}_{2} \mathrm{O}_{3}$ films. Rus. J. Phys. Chem., 84, 1706-1711

Belysheva, T., Spiridonova, E., Gromov, V., Gerasimov, G., \& Trakhtenberg, L. (2010b). Sensor properties of nanocomposite oxides $\mathrm{SnO}_{2} \cdot \mathrm{In}_{2} \mathrm{O}_{3}$ in detecting of hydrogen in air. Rus. J. Phys. Chem., 84, 1554-1559

Belysheva, T., Gromov, V., Gerasimov, G., Spiridonova, E., Bondarenko, S., \& Trakhtenberg, L. (2011). Sensor properties of $\mathrm{SnO}_{2}+\mathrm{In}_{2} \mathrm{O}_{3}$ films in detecting of $\mathrm{CO}$ in air. Rus. J. Phys. Chem., 85, No 6.

Blackman, J. (1995). Growth models for discontinuous films. Physica A, 220, 85-98

Chowdhuri, A., Sharma, P., Gupta, V., \& Sreenivas, K. (2002). $\mathrm{H}_{2} \mathrm{~S}$ gas sensing mechanism of $\mathrm{SnO}_{2}$ films with ultrathin $\mathrm{CuO}$ dotted islands, J.Applied Physics, 92, 2172-2180. http://dx.doi.org/10.1063/1.1490154

Chowdhuri, A., Gupta, V., Sreenivas, K., Kumar, R., Mozumdar, S., \& Patanjali, P. K. (2004). Response speed of $\mathrm{SnO}_{2}$-based $\mathrm{H} 2 \mathrm{~S}$ gas sensors with $\mathrm{CuO}$ nanoparticles, Appl. Physics Letters, 84, 1180-1182. http://dx.doi.org/10.1063/1.1646760

Comini, E., Ferroni, M., Guidi, V., Faglia, G., Martinelli, G., \& Sberveglieri, G. (2002). Nanostructured mixed oxides compounds for gas sensing applications. Sensors and Actuators, B84, 26-32. http://dx.doi.org/10.1016/S0925-4005(02)00006-0

Du, T., \& Ilegbusi, O. (2004). Synthesis and morphological characterization on PVP/ZnO nano hybrid films. $J$. Materials Science, 39, 6105-6109. http://dx.doi.org/10.1023/B:JMSC.0000041712.35581.4c

Edelman, F., Hahn, H., Seifried, S., Alof, C., Hoches, H., Balogh, A., Werner, P., Zakrzewska, K., Radecka, M., Pasierb, P., Chack, A., Mikhelashvili, V., \& Eisenstein, G. (2000). Structural evolution of $\mathrm{SnO}_{2}--\mathrm{TiO}_{2}$ nanocrystalline films for gas sensors. Materials Science and Engineering, B69-70, 386-391. http://dx.doi.org/10.1016/S0921-5107(99)00282-2 
Efros, A. (1982). Physics and Geometry of Disorder (Fizika i geometria besporjadka). Nauka, Moscow

Gerasimov, G., \& Trakhtenberg, L. (2007). Vapor Deposited Composite Films Consisting of Dielectric Matrix with Metal/Semiconductor Nanoparticles. In: Physico-Chemical Phenomena in Thin Films and at Solid Surfaces, Ed. L.I. Trakhtenberg, S. H. Lin and O.J. Ilegbusi, 456-503, Elsevier Inc., Amsterdam.

Gleiter, H., Weissmuller, J., Wollersheim, O., \& Wurschum, R. (2001). Nanocrystalline materials: A way to solids with tunable electronic structures and properties? Acta mater., 49, 737-745. http://dx.doi.org/10.1016/S1359-6454(00)00221-4

Godovski, D. (1995). Electron behavior and magnetic properties of polymer nanocomposites. Adv. Polymer Sci., 119, 79-122. http://dx.doi.org/10.1007/BFb0021281

Haouas, A., Nogier, J., \& Fraissard, J. (1993). On the kinetics of the oxidation of traces of $\mathrm{CO}$ on $\mathrm{CuO}-\mathrm{SnO}_{2}$ catalysts. Catalysis Today, 17, 63-69. http://dx.doi.org/10.1016/0920-5861(93)80008-O

He, H., Ho, S., Wu, N., Chen, L., \& Wang, Z. (2007) Electrical and photoelectrical performance of nano-diode based on ZnO nanowires. Chemical Physics Letters, 435, 119-121. http://dx.doi.org/10.1016/j.cplett.2006.12.061

Hoefer, U., Frank, J., \& Fleischer M. (2001). High temperature $\mathrm{Ga}_{2} \mathrm{O}_{3}$-gas sensors and $\mathrm{SnO}_{2}$-gas sensors: a comparison. Sensors and Actuators, B78, 6-11. http://dx.doi.org/10.1016/S0925-4005(01)00784-5

Ivanovskaya, M., Kotsikau, D., Faglia, G., \& P. Nelli. (2003). Influence of chemical composition and structural factors of $\mathrm{Fe}_{2} \mathrm{O}_{3} / \mathrm{In}_{2} \mathrm{O}_{3}$ sensors on their selectivity and sensitivity to ethanol. Sensors and Actuators, B96, 498-503. http://dx.doi.org/10.1016/S0925-4005(03)00624-5

Kim, K., Cho, P., Kim, S., Lee, J., Kang, C., Kim, J., \& Yoon, S. (2007). The selective detection of C2H5OH using $\mathrm{SnO}_{2}-\mathrm{ZnO}$ thin film gas sensors prepared by combinatorial solution deposition. Sensors and Actuators, B123, 318-324. http://dx.doi.org/10.1016/j.snb.2006.08.028

Klein, A. (2000). Electronic properties of $\mathrm{In}_{2} \mathrm{O}_{3}$ surfaces. Appl. Phys. Lett., 77, 2009-2015. http://dx.doi.org/10.1063/1.1312199

Klein, A., Korber, C., Wachau, A., Säuberlich, F., Gassenbauer, Y., Harvey, S., Proffit, D., \& Mason, T. (2010). Transparent Conducting Oxides for Photovoltaics: Manipulation of Fermi Level, Work Function and Energy Band Alignment. Materials, 3, 4892-4914. http://dx.doi.org/10.3390/ma3114892

Kohl, D. (1989). Surface processes in the detection of reducing gases with $\mathrm{SnO}_{2}$ based devices. Sensors and Actuators, 18, 71-113. http://dx.doi.org/10.1016/0250-6874(89)87026-X

Korotcenkov, G., Brinzari, V., DiBattista, M., Schwank, J., \& Vasiliev A. (2001). Peculiarities of $\mathrm{SnO}_{2}$ thin film deposition by spray pyrolisis for gas sensor application. Sensors and Actuators, B77, 244-252. http://dx.doi.org/10.1016/S0925-4005(01)00741-9

Korotcenkov, G., Brinzari, V., Cerneavschi, A., Ivanov, M., Cornet, A., Morante, J., Cabot, A., \& Arbiol, J. (2004). $\mathrm{In}_{2} \mathrm{O}_{3}$ films deposited by spray pyrolysis: gas response to reducing $\left(\mathrm{CO}, \mathrm{H}_{2}\right)$ gases. Sensors and Actuators, B98, 122-129. http://dx.doi.org/10.1016/j.snb.2003.09.009

de Lacy Costello, B., Ewen, R., Guernion, N., \& Ratcliffe, N. (2002). Highly sensitive mixed oxide sensors for the detection of ethanol. Sensors and Actuators, B87, 207-210. http://dx.doi.org/10.1016/S0925-4005(02)00220-4

Lee, H., Song, J., Yoon, Y., Kim, T., Kim, K., \& Choi, W. (2001). Enhancement of CO sensitivity of indium oxide-based semiconductor gas sensor through ultra-thin cobalt adsorption. Sensors and Actuators, B79, 200-205. http://dx.doi.org/10.1016/S0925-4005(01)00876-0

Manoj, P., Joseph, B., Vaidyan, V., Sumangala, D., \& Amma, D. (2007). Preparation and characterization of indium-doped tin oxide thin films. Ceramics International, 33, 273-278. http://dx.doi.org/10.1016/j.ceramint.2005.09.016

Matsushima, S., Teraoka, Y., Miura, N., \& Yamazoe, N. (1988). Electronic Interaction between Metal Additives and Tin Dioxide in Tin Dioxide-Based Gas Sensors. Japanese Journal of Applied Physics, 27(10), 1798-1802. http://dx.doi.org/10.1143/JJAP.27.1798

Mehta, B., \& Singh, V. (2005). Structural, electrical and gas-sensing properties of $\operatorname{In}_{2} \mathrm{O}_{3}$ : Ag composite nanoparticle layers. PRAMANA - journal of physics, 65(5), 949-958. 
Nanto, H., Morita, T., Habara, H., Kondo, K., Douguchi, Y., \& Minami, T. (1996). Doping effect of $\mathrm{SnO}_{2}$ on gas sensing characteristics of sputtered $\mathrm{ZnO}$ thin film chemical sensor. Sensors and Actuators, B35-36, 384-387. http://dx.doi.org/10.1016/S0925-4005(97)80101-3

Neri, G., Bonavita, A., Micali, G., Rizzo, G., Pinna, N., Niederberger, M., \& Ba, J. (2008). Effect of the chemical composition on the sensing properties of $\mathrm{In}_{2} \mathrm{O}_{3}-\mathrm{SnO}_{2}$ nanoparticles synthesized by a non-aqueous method. Sensors and Actuators, B130, 222-230. http://dx.doi.org/10.1016/j.snb.2007.07.141

Pomogailo, A., Rozenberg, A., \& Uflyand, I. (2000). Nanoparticles of metals in polymers, Chemistry, Moscow.

Sergeev, G., Zagorsky, V., Petrukhina, M., Zav`yalov, S., Grigor`ev, E., \& Trakhtenberg, L. (1997). Preliminary study of the interaction of mtal nanoparticle-containing poly-p-xylylene films with ammonia. Anal. Commun., 34, 113-116. http://dx.doi.org/10.1039/a700431a

Shen, Y., \& Zhang, T. (1993). Preparation, structure and gas-sensing properties of ultramicro $\mathrm{ZnSnO}_{3}$ powder. Sensors and Actuators, B12, 5-9. http://dx.doi.org/10.1016/0925-4005(93)85003-S

Shouli, B., Liangyuan, C., Pengchenget, Y., Ruixian, L., Aifan C., \& Liu, C. (2008). Sn/In/Ti nanocomposite sensor for $\mathrm{CH}_{4}$ detection. Sensors and Actuators, B135, 1-6. http://dx.doi.org/10.1016/j.snb.2008.06.051

Shouli, B., Dianqinga, L., Dongmei, H., Ruixian, L., Aifan, C., \& Liu, C. (2010). Preparation, characterization of $\mathrm{WO}_{3}-\mathrm{SnO}_{2}$ nanocomposites and their sensing properties for $\mathrm{NO}_{2}$. Sensors and Actuators, B150, 749-755. http://dx.doi.org/10.1016/j.snb.2008.06.051.

Solis, J., \& Lantto, V. (1995). A study of gas-sensing properties of sputtered $\alpha$-SnWO4 thin films. Sensors and Actuators, B 24/25, 591-595. http://dx.doi.org/10.1016/0925-4005(95)85129-1

Szklarski, Z., Zakrzewska, K., \& Rekas, M. (1989). Thin oxide films as gas sensors. Thin Solid Films, 174, 269-275. http://dx.doi.org/10.1016/0040-6090(89)90901-2

Tang, H., Yan, M., Zhang, H., Li, S., Ma, X., Wang, M., \& Yang, D. (2006). A selective $\mathrm{NH}_{3}$ gas sensor based on $\mathrm{Fe}_{2} \mathrm{O}_{3}-\mathrm{ZnO}$ nanocomposites at room temperature. Sensors and Actuators, B114, 910-915. http://dx.doi.org/10.1016/j.snb.2005.08.010

Thangaraju, B. (2002). Structural and electrical studies on highly conducting spray deposited fluorine and antimony doped $\mathrm{SnO}_{2}$ thin films from $\mathrm{SnCl} 2$ precursor. Thin Solid Films, 402, 71-78. http://dx.doi.org/10.1016/S0040-6090(01)01667-4

Trakhtenberg, L., Axelrod, E., Gerasimov, G., Grigoriev, A., Grigoriev, E., Zav'yalov S., \& Feldman, Yu. (1999). Sensor properties, photoconductivity and dielectric behaviour of poly-p-xylylene films containing semiconductor nanocrystals. Sci. Isr. - Technol. Adv., 1, 572 -578.

Trakhtenberg L., \& Gerasimov, G. (2005). Metal-containing Polymers: Cryochemical Synthesis, Structure and Physicochemical Properties. In: Metal/Polymer Nanocomposites. 37-56. Ed. G. Carotenuto \& L. Nicolais, John Wiley \& Sons, New York.

Vorontsov, P., Golubeva, E., Grigor'ev, E., Zavyalov, S., Zavyalova L., \& Trakhtenberg, L. (1998). Gas-Sensitive and Catalytic Properties of Ensambles of Interacting Palladium Nanoparticles. Russ. J. Phys. Chem., 72, 1742-1744.

Woehrle, D. (1996). Metal Complexes, Zero-Valent Metals and Metal Clusters Physically Connected with Macromolecular Compounds. In: Macromolecule-Metal Complexes, Ed. F. Ciardelli, E. Tsushida, D. Woehrle, Springer Verlag, Berlin, Heidelberg,

Xu, L., Song, H., Dong, B., Wang, Y., Chen, J., \& Bai, X. (2010). Preparation and Bifunctional Gas Sensing Properties of Porous $\mathrm{In}_{2} \mathrm{O}_{3}-\mathrm{CeO}_{2}$ Binary Oxide Nanotubes. Inorg. Chem., 49, 10590-10597. http://dx.doi.org/10.1021/ic101602aPMid:20949903

Yamaura, H., Jinkawa, T., Tamaki, J., Moriya, K., Miura, N., \& Yamazoe, N. (1996). Indium oxide based gas sensor for selective detection of CO. Sensors and Actuators, B35-36, 325-332. http://dx.doi.org/10.1016/S0925-4005(97)80090-1

Yamazoe, N., \& Shimanoe, K. (2008). Theory of power laws for semiconductor gas sensors. Sensors and Actuators, B128, 566-573. http://dx.doi.org/10.1016/j.snb.2007.07.036

Yamazoe, N., \& Shimanoe, K. (2009). Receptor Function and Response of Semiconductor Gas Sensor. Journal of Sensors, ID 875704 
Yang, H., Zhang, X., \& Tang, A. (2006). Mechanosynthesis and gas-sensing properties of $\mathrm{In}_{2} \mathrm{O}_{3} / \mathrm{SnO}_{2}$ nanocomposites. Nanotechnology, 17, 2860-2864. http://dx.doi.org/10.1088/0957-4484/17/12/006

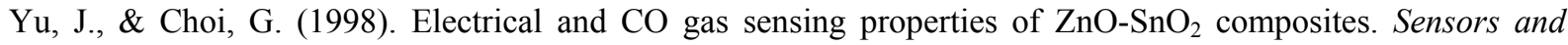
Actuators, B52, 251-256. http://dx.doi.org/10.1016/S0925-4005(98)00275-5

$\mathrm{Yu}$, J., \& Choi, G. (2001).Selective $\mathrm{CO}$ gas detection of $\mathrm{CuO}$ - and $\mathrm{ZnO}-$ doped $\mathrm{SnO}_{2}$ gas sensor. Sensors and Actuators, B75, 56-61. http://dx.doi.org/10.1016/S0925-4005(00)00742-5

Zaporojtchenko V., Behnke K., Thran A., Strunskus, T., \& Faupel, F. (1999). Condensation coefficients and initial stages of growth for noble metals deposited onto chemically different polymer surfaces. Appl. Surf. Sci., 144-145, 355-359. http://dx.doi.org/10.1016/S0169-4332(98)00826-5

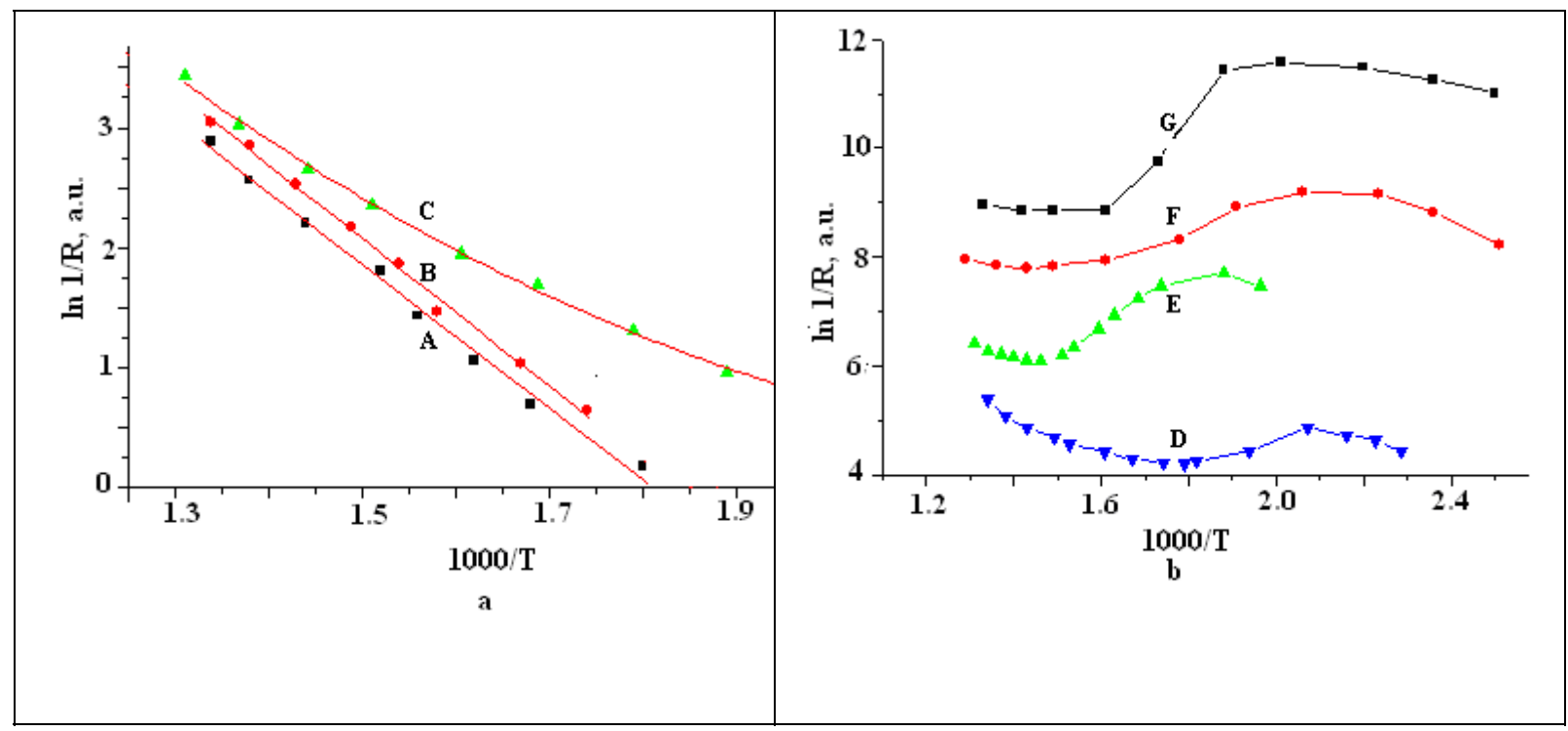

Figure 1 . Temperature dependence of conductivity $1 / \mathrm{R}$ in arbitrary units, where $\mathrm{R}$ is film resistance, for nanocrystalline $\mathrm{SnO}_{2}$ film (A); $\mathrm{SnO}_{2}+\mathrm{In}_{2} \mathrm{O}_{3}$ composite films with different $\mathrm{In}_{2} \mathrm{O}_{3}$ concentrations (wt.\%)- $6 \%$ (B); $12 \%(C) ; 20 \%(D) ; 37 \%(E) ; 50 \%(F)$; nanocrystalline $\operatorname{In}_{2} \mathrm{O}_{3}$ film $(\mathrm{G})$ 

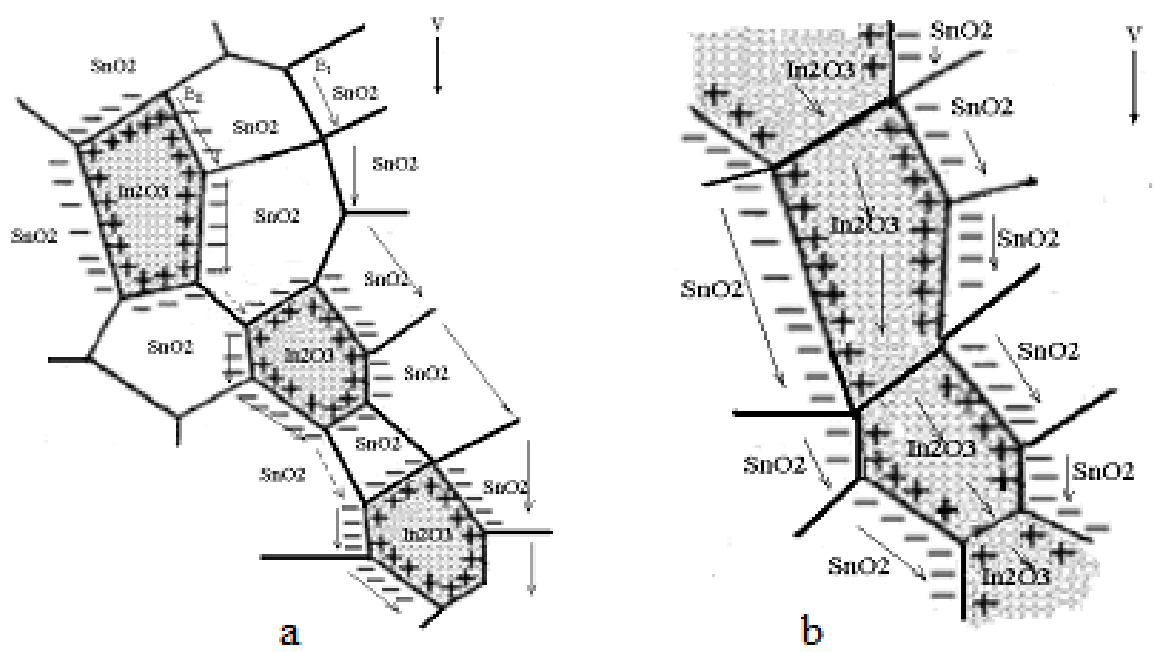

Figure 2. Schemattic representation of electron movement in $\mathrm{SnO}_{2}+\mathrm{In}_{2} \mathrm{O}_{3}$ composite film with concentration of $\mathrm{In}_{2} \mathrm{O}_{3}$ below (a) and above (b) of the percolation threshold of $\operatorname{In}_{2} \mathrm{O}_{3}$ particles in an electric field $\mathrm{V}$. Arrows indicate the movement of electrons through a system of $\mathrm{SnO}_{2}$ nanocrystals, including uncharged region with conductivity $\mathrm{BI}$ and negatively charged region with conductivity BII, as well as through conducting $\operatorname{In}_{2} \mathrm{O}_{3}$ cluster. The activation energy of the conductivity is determined by the barriers at the boundaries between nanocrystals such that electron transfer within the charged crystal in the path BII (dashed arrows) has no effect on the activation energy of conduction along this path

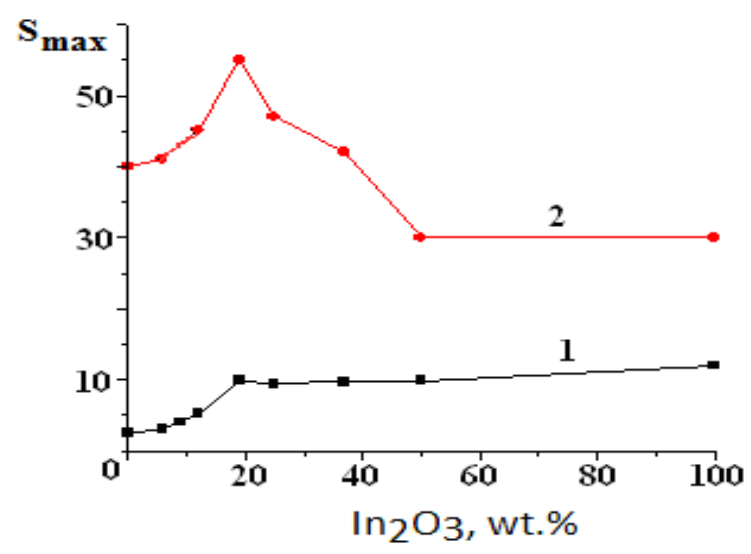

Figure 3. Variation of maximum sensitivity $\mathrm{S}_{\max }$ of $\mathrm{SnO}_{2}+\mathrm{In}_{2} \mathrm{O}_{3}$ composite sensor with $\operatorname{In}_{2} \mathrm{O}_{3}$ concentration for detection of $0.46 \% \mathrm{CO}(1)$, and $2 \% \mathrm{H}_{2}$ (2) 


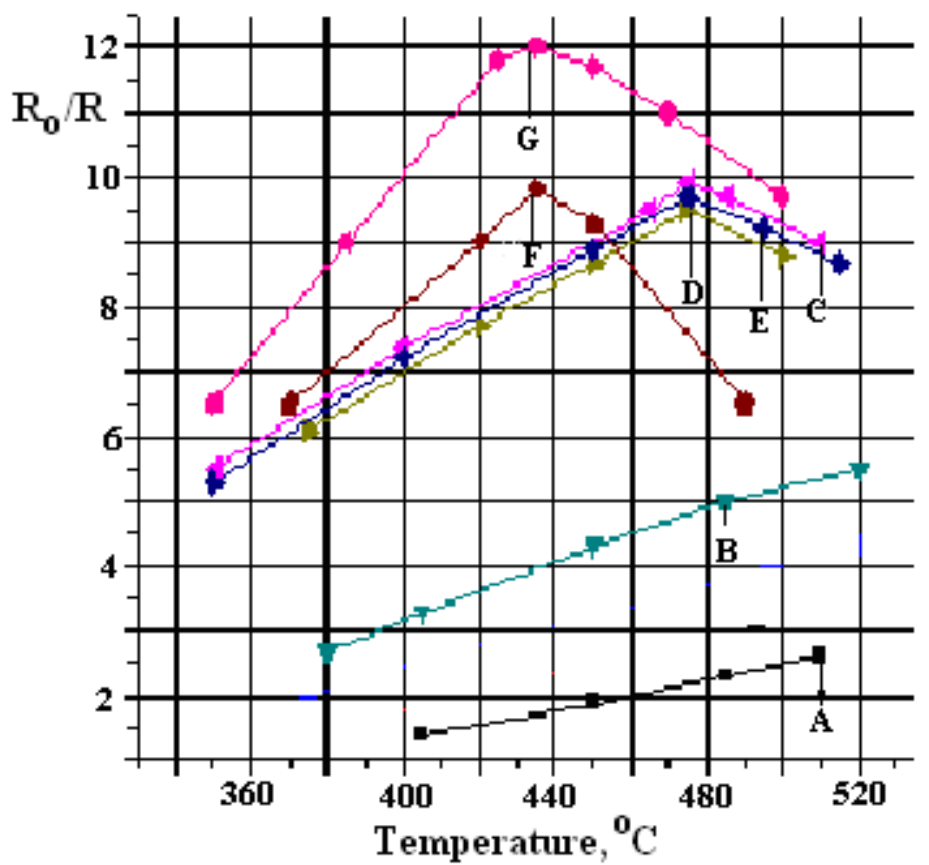

Figure 4. Temperature dependence of $\mathrm{SnO}_{2}+\mathrm{In}_{2} \mathrm{O}_{3}$ composite sensor sensitivity $\mathrm{S}=\mathrm{R}_{\mathrm{o}} / \mathrm{R}\left(\mathrm{R}_{\mathrm{o}}\right.$ and $\mathrm{R}$ are the sensor resistance in pure air and air containing analyzed gas, respectively) in detecting $0.46 \% \mathrm{CO}$, for varying $\mathrm{In}_{2} \mathrm{O}_{3}$ concentration (wt. \%): 0 (A); 12\% (B); 20\% (C); 25\% (D); 37\% (E); 50\%(F); 100\% (G)
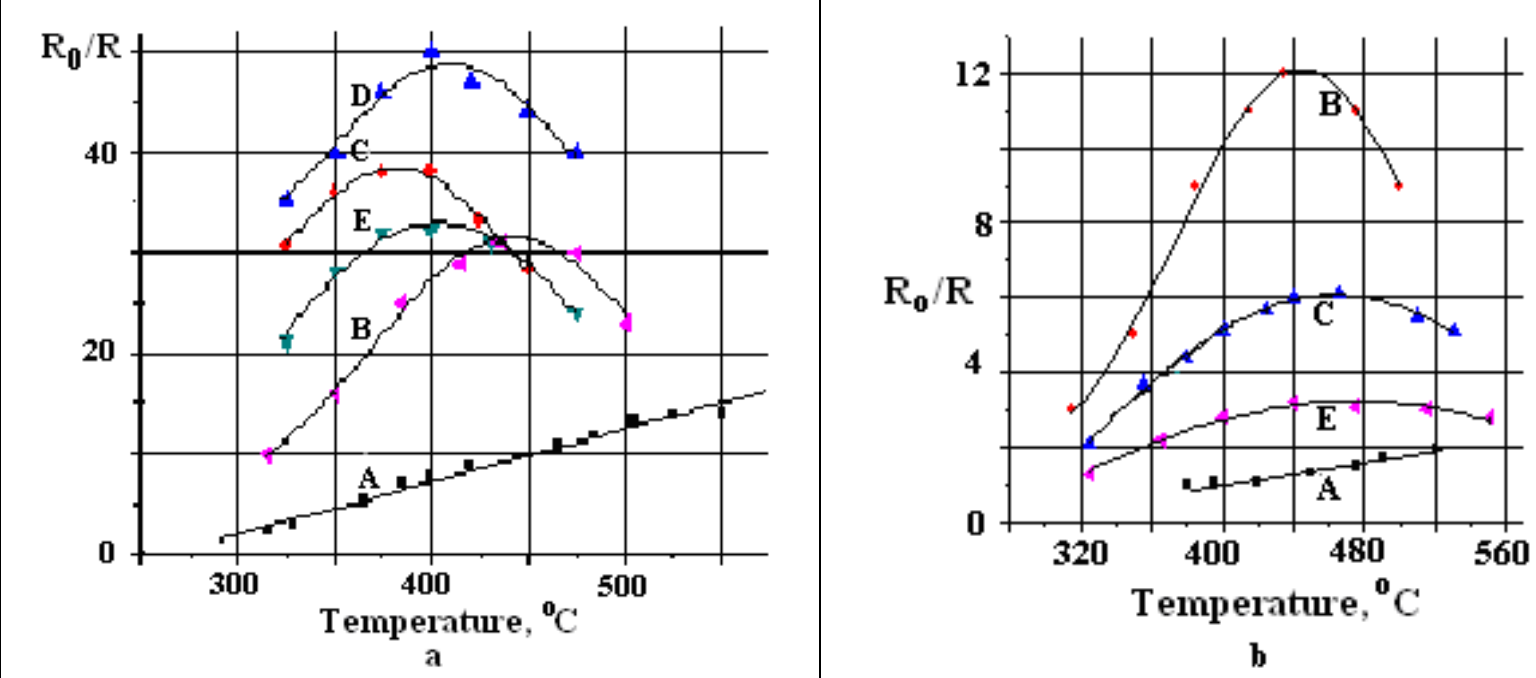

b

Figure 5. Temperature dependence of sensor sensitivity $S=R_{0} / R\left(R_{0}\right.$ and $R$ are sensor resistance in pure air and in air containing analyzed gas, respectively) in detecting $2 \% \mathrm{H}_{2}$ (a) and $0.46 \% \mathrm{CO}$ (b) for a variety of films: $\mathrm{ZnO}(\mathrm{A}) ; \mathrm{In}_{2} \mathrm{O}_{3}(\mathrm{~B}) ; \mathrm{In}_{2} \mathrm{O}_{3}+\mathrm{ZnO}$ composite sensors with different wt. \% of $\mathrm{ZnO}: 1 \%$ (C); 3\% (D); 10\% (E) 